\title{
Analysis of the influence of the anisotropy induced by cold rolling on duplex and super-austenitic stainless steels
}

\author{
Angelo Finelli, Martino Labanti \\ ENEA - Unità Tecnica Tecnologie dei Materiali Faenza
}

RIASSUNTO. Questo articolo contiene i risultati della caratterizzazione meccanica eseguita su due tipi di acciaio inossidabile (duplex $6 \% \mathrm{Ni}, 22 \% \mathrm{Cr}$ e super-austenitico $31 \% \mathrm{Ni}, 28 \% \mathrm{Cr}$ ) utilizzati per la fabbricazione di tubi impiegati nella produzione di idrocarburi.

L'attività è stata svolta con l'obiettivo primario di valutare l'effetto dell'anisotropia provocata sul manufatto dalla laminazione a freddo, considerando le caratteristiche meccaniche degli acciai misurate nelle tre direzioni principali.

Considerata la limitata sezione del manufatto, il metodo ed i campioni utilizzati per le prove non fanno riferimento a nessuna normativa. La procedura messa a punto ha previsto infatti l'utilizzo di estensimetri elettrici a resistenza, incollati sui campioni, per la misura della deformazione durante le prove.

ABSTRACT. This report contains the results obtained from the mechanical characterization tests carried out on two different stainless steel (duplex $6 \% \mathrm{Ni}, 22 \% \mathrm{Cr}$ and super-austenitic $31 \% \mathrm{Ni}, 28 \% \mathrm{Cr}$ ) used for the manufacturing of pipes which are employed in the oil production.

The activity has been performed in order to evaluate the effects of anisotropy, induced by cold rolling, on the mechanical characteristics of the investigated steels, measured in the three main directions.

Considering the small size of the component, the method and the specimens used for the tests were not the standard one. The procedure carried out provided the strain measurement of the specimen during testing by means of resistive strain gages, bonded on the specimens.

KEYwORDS. Anisotropy; Cold rolling; Mechanical properties; Strain gages.

\section{TEST AIM}

he main goal of this activity is the evaluation the effects of the cold rolling process on the mechanical properties of two different stainless steels: a duplex stainless steel and a superaustenitic stainless steels. The main problem to be considered was the reduced specimens dimensions, for all the investigated testing directions: considering that no standards could be followed, it was necessary to optimize a customized testing procedure. 


\section{INVESTIGATED MATERIALS}

T nvestigated steel are largely used in petrochemical industry (e.g., pipes manufacturing).

The first investigated steel is a duplex stainless steel (chemical composition in Tab 1). This tubular shaped material, sized $115 \times 9 \mathrm{~mm}$, has been subjected to the following processing cycle:

- Hot extrusion.

- Water cooling.

- Annealing at $1050^{\circ} \mathrm{C}$.

- Water cooling.

In order to obtain the final pipe dimensions $(88.9 \times 6.5 \mathrm{~mm})$, a cold rolling treatment was performed.

\begin{tabular}{ccccccccccccc}
\hline Mat. & $\mathrm{C}$ & $\mathrm{Mn}$ & $\mathrm{Si}$ & $\mathrm{S}$ & $\mathrm{P}$ & $\mathrm{Ni}$ & $\mathrm{Cr}$ & $\mathrm{Mo}$ & $\mathrm{Cu}$ & $\mathrm{V}$ & $\mathrm{Al}$ & $\mathrm{N}$ \\
$\mathrm{A} 1$ & 0.038 & 1.37 & 0.40 & 0.001 & 0.013 & 5.54 & 21.93 & 3.00 & 0.035 & 0.040 & 0.045 & 0.140 \\
$\mathrm{~A} 1 \mathrm{~L}$ & 0.038 & 1.37 & 0.40 & 0.001 & 0.013 & 5.54 & 21.93 & 3.00 & 0.035 & 0.040 & 0.045 & 0.140 \\
5 & 0.018 & 1.81 & 1.01 & 0.002 & 0.017 & 32.60 & 26.47 & 3.55 & 1.01 & - & - & 0.098 \\
4L & 0.021 & 1.28 & 0.47 & 0.003 & 0.018 & 31.15 & 26.80 & 3.34 & 1.28 & 0.086 & 0.047 & 0.058 \\
\hline
\end{tabular}

Table 1: Investigated steels chemical compositions.

Fig 1 and 2 show duplex stainless steel microstructure, considering longitudinal, transversal and radial sections, respectively before and after the cold rolling treatment (respectively named as "A1" and "A1L").

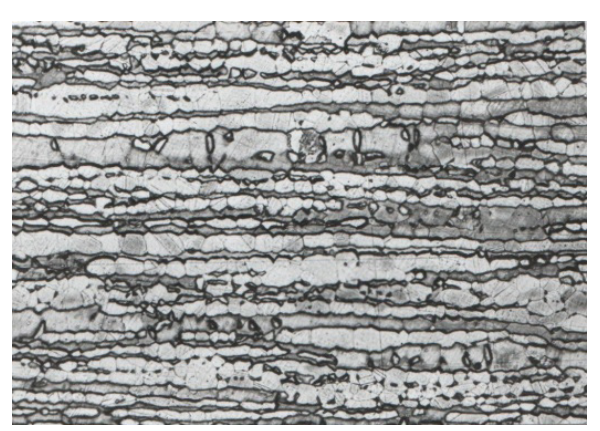

Figure 1a: "A1" steel microstructure Longitudinal section (x 200)

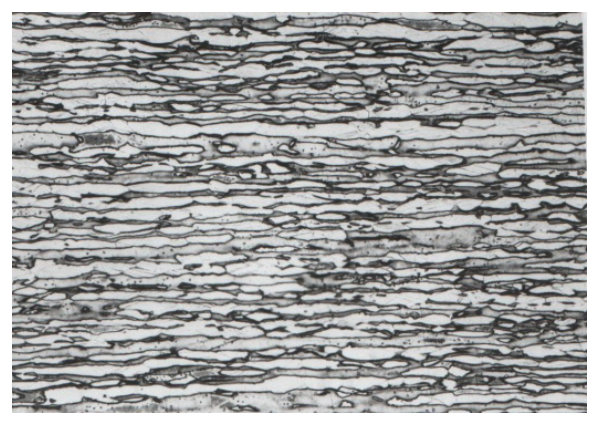

Figure 2a: "A1L" steel microstructure Longitudinal section (x 200).

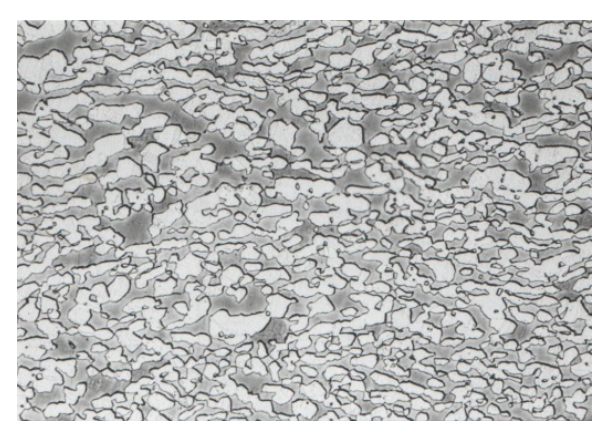

Figure 1b: "A1" steel microstructure Transversal section (x 200)

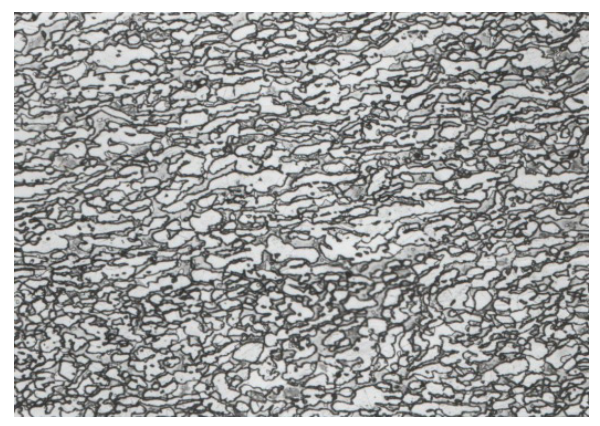

Figure 2b: "A1L” steel microstructure Transversal section (x 200).

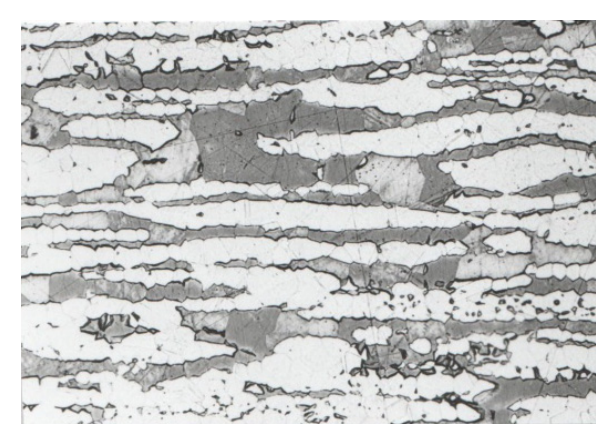

Figure 1c: "A1" steel microstructure Radial section (x 200)

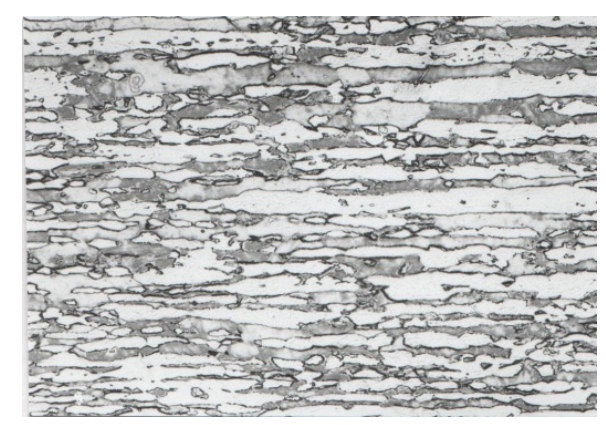

Figure 2c: "A1L” steel microstructure Radial section (x 200).

The second investigated steel is a super-austenitic stainless steel (chemical composition in Tab 1. This tubular-shaped material, sized $121 \times 8.25 \mathrm{~mm}$, has been subjected to the following processing cycle:

- Hot extrusion.

- Water cooling. A stainless steel with a similar chemical composition was also investigated after a cold rolling treatment, obtaining a
tubular-shaped material sized $88.9 \times 6.5 \mathrm{~mm}$ ). 
Fig. 3 and 4 show super-austenitic stainless steel microstructure, considering longitudinal, transversal and radial sections, respectively before and after the cold rolling treatment (respectively named as "5" and "4L").

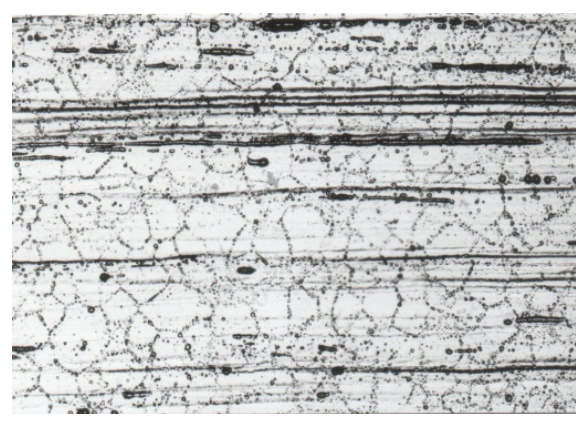

Figure 3a: " 5 " steel microstructure Longitudinal section (x 200).

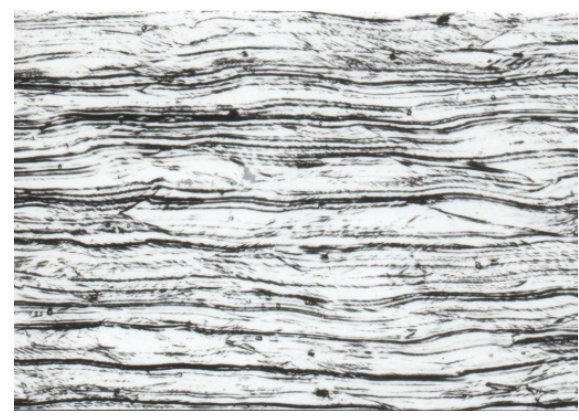

Figure 4a: "4L" steel microstructure Longitudinal section (x 200).

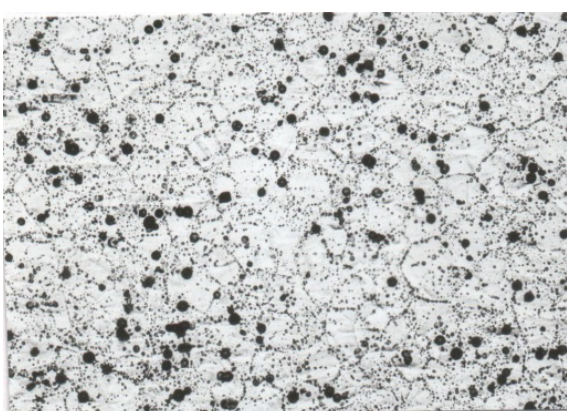

Figure 3b: " 5 " steel microstructure Transversal section (x 200).

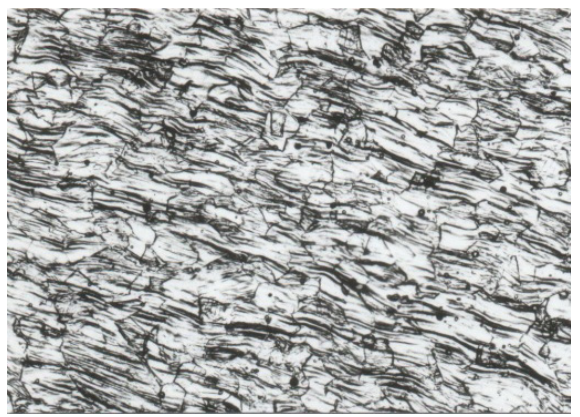

Figure 4b: "4L" steel microstructure Transversal section (x 200).

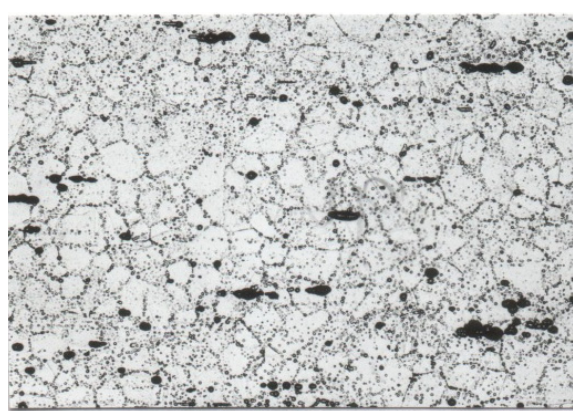

Figure 3c: " 5 " steel microstructure Radial section (x 200).

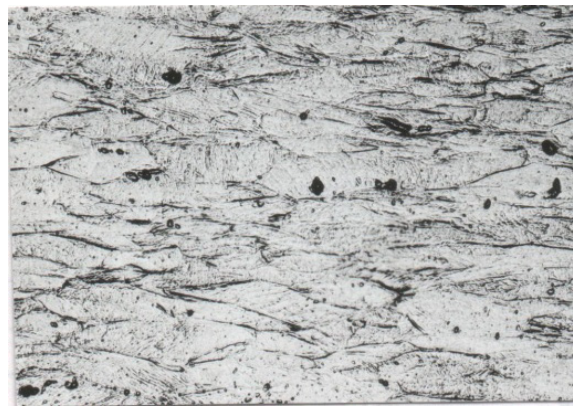

Figure 4c: "4L" steel microstructure Radial section (x 200).

\section{EXPERIMENTAL PROCEDURE}

$\mathrm{D}$

ue to pipes thickness, sampling according to standards requirements was impossible for the investigating directions $\mathrm{T}$ and $\mathrm{R}$ (longitudinal $\mathrm{L}$, transversal $\mathrm{T}$, radial $\mathrm{R}$ ). It was only possible to manufacture $\mathrm{L}$ direction specimens according to the ASTM E8 standard (Fig. 5) and they were named as SL specimens, for all the four investigated steels.

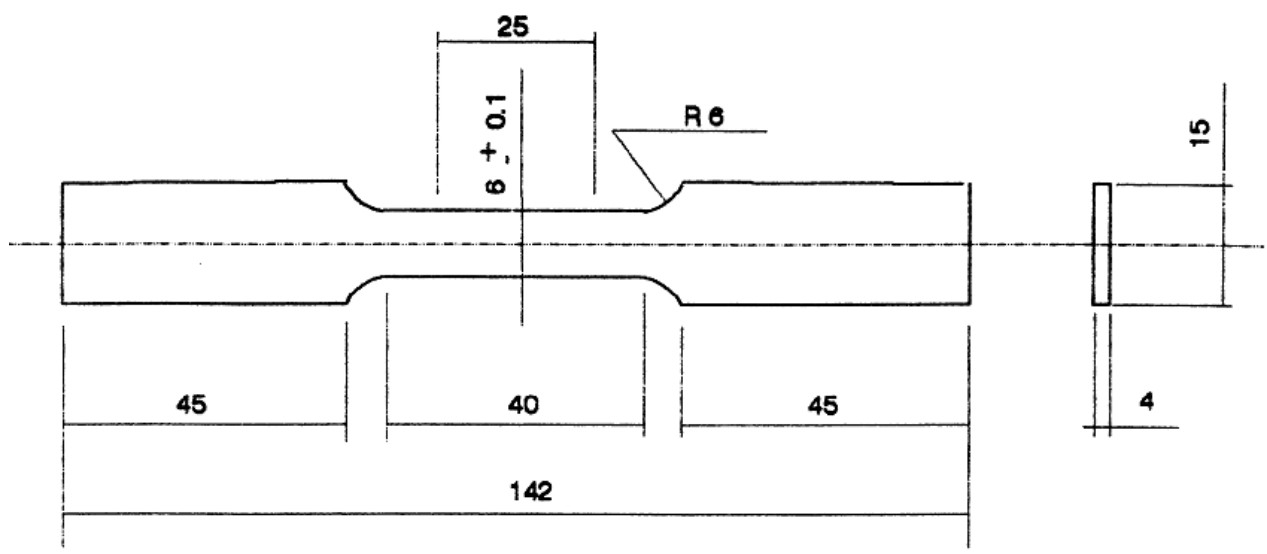

Figure 5: Standard specimen (S) for tensile test.

Considering $\mathrm{L}$ and $\mathrm{T}$ directions, $5 \mathrm{~mm}$ gage length tensile specimens (named as "B", Fig. 6) were obtained for all the investigated materials. Depending on the sampling direction, these specimens were named as "BL" or "BT". 


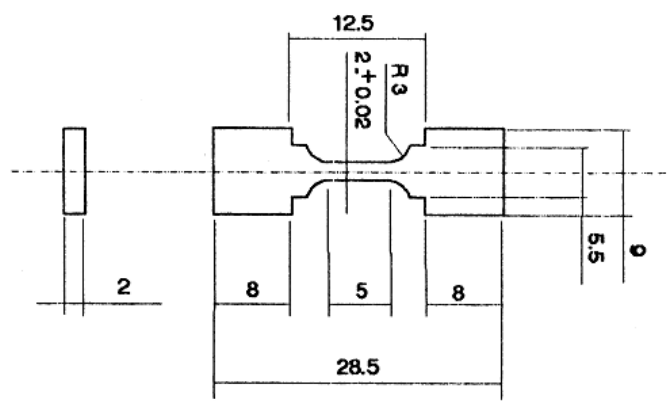

Figure 6: Specimen short gage length (B) for tensile test.

Finally, for all the investigated directions ( $\mathrm{L}, \mathrm{T}$ and $\mathrm{R}$ ) and the two cold rolled steels, compression specimens were obtained (Fig. 7): they were named as "CL", "CT" or "CR" depending on the sampling direction.

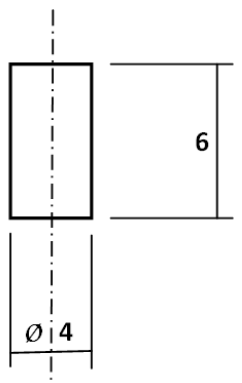

Figure 7: Specimen for compression test (C).

Table 2 shows the test matrix. On the basis of the test results obtained in $\mathrm{L}$ direction using both standard specimens (S), short gage length specimens (B) and compression specimens (B), it is possible to evaluate the evolution of the mechanical properties in the other two directions, where it is impossible to obtain standard specimens.

\begin{tabular}{|c|c|c|c|c|c|c|}
\hline \multirow{2}{*}{ Specimen } & \multirow{2}{*}{$\frac{\text { Standard (S) }}{\mathrm{L}}$} & \multicolumn{2}{|c|}{ Short gage length (B) } & \multicolumn{3}{|c|}{ Compression (C) } \\
\hline & & $\mathrm{L}$ & $\mathrm{T}$ & $\mathrm{L}$ & $\mathrm{T}$ & $\mathrm{R}$ \\
\hline A1 & $\uparrow$ & $\uparrow$ & $\uparrow$ & & & \\
\hline A1L & $\uparrow$ & $\uparrow$ & $\uparrow$ & $\uparrow$ & $\uparrow$ & $\uparrow$ \\
\hline 5 & $\uparrow$ & $\uparrow$ & $\uparrow$ & & & \\
\hline $4 \mathrm{~L}$ & $\uparrow$ & $\uparrow$ & $\uparrow$ & $\uparrow$ & $\uparrow$ & $\uparrow$ \\
\hline
\end{tabular}

Table 2: Test matrix.

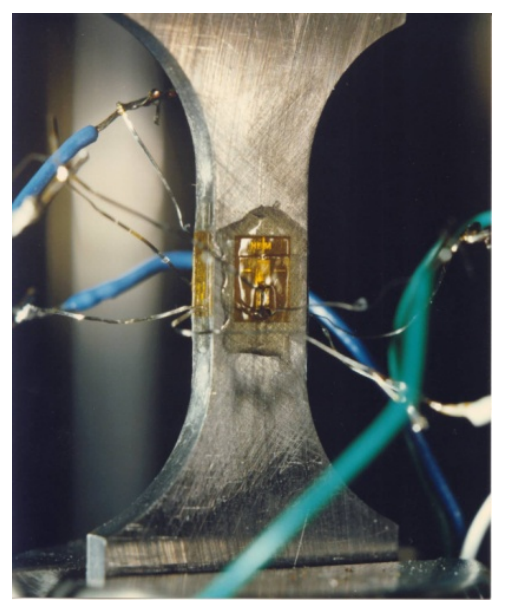

Figure 8: Specimen (B) during tensile test. 
Both specimens "B" and "C" did not allow to use conventional extensometers; strain measurements were performed by means of resistive strain gages: these strain gages were able to detect strains up to 5\% max. [Fig. 8].

All the tests were carried out in compliance with the ASTM A 370 standards according to the methods reported in ASTM E 8 and E 9 [1, 2]. At least, three tests were performed for all the investigated conditions.

\section{EXPERIMENTAL RESULTS}

onsidering standard specimens $(\mathrm{S})$, the following parameters were considered:

- $\quad$ Yield strength at $0.2 \%\left(\sigma_{\mathrm{s}(0.2 \%)}\right)$.

- Ultimate Tensile Strength $\left(\sigma_{\mathrm{u}}\right)$.

- $\quad$ Elongation measured on a base of $25 \mathrm{~mm}$ (A\% $25 \mathrm{~mm})$.

Mean values are shown in Tab. 3 .

\begin{tabular}{cccc}
\hline & $\sigma_{\mathrm{s}(0.2 \%)}[\mathrm{MPa}]$ & $\sigma_{\mathrm{m}}[\mathrm{MPa}]$ & $\mathrm{A}_{(25)}[\%]$ \\
A1SL & 477 & 764 & 49 \\
A1LSL & 1046 & 1110 & 19 \\
5SL & 339 & 683 & 59 \\
4LSL & 833 & 925 & 19 \\
\hline
\end{tabular}

Table 3: Tensile test average results of standard specimen (S)

The same parameters were also considered with the "short gage length" (B) specimens, with a difference in the elongation measurement (a base of $12.5 \mathrm{~mm}$ instead of $25 \mathrm{~mm}$ ) Results are summarized in Tab. 4.

\begin{tabular}{c|ccc}
\hline & $\sigma_{\mathrm{s}(0.2 \%)}[\mathrm{MPa}]$ & $\sigma_{\mathrm{m}}[\mathrm{MPa}]$ & $\mathrm{A}_{(12.5)}[\%]$ \\
A1BL & 491 & 771 & 27 \\
A1BT & 507 & 772 & 25 \\
A1LBL & 971 & 1063 & 16 \\
A1LBT & 908 & 1111 & 13 \\
5BL & 308 & 669 & 36 \\
5BT & 337 & 696 & 34 \\
4LBL & 830 & 915 & 16 \\
4LBT & 749 & 916 & 16 \\
\hline
\end{tabular}

Table 4: Tensile test average results of short gage length specimen (B).

Considering compression specimens $(\mathrm{C})$, it was only possible to measure the yield strength value at $0.2 \%$, since both the specimen geometry and the material ductility prevent the other parameters from being detected. Mean values are shown in Tab. 5

\begin{tabular}{cc}
\hline & $\sigma_{\mathrm{s}(0.2 \%)}[\mathrm{MPa}]$ \\
\hline A1LCL & 860 \\
A1LCT & 1081 \\
A1LCR & 1065 \\
4LCL & 714 \\
4LCT & 938 \\
4LCR & 866 \\
\hline
\end{tabular}

Table 5: Compression test average results (C).

Tab. 6 summarizes all the experimental results for all the investigated steels and all the considered specimens. 


\begin{tabular}{|c|c|c|c|c|c|c|c|}
\hline Specimen & Standard (S) & & (B) & & npress & & \\
\hline Steel & $\mathrm{L}$ & $\mathrm{L}$ & $\mathrm{T}$ & $\mathrm{L}$ & $\mathrm{T}$ & $\mathrm{R}$ & \\
\hline & 477 & 491 & 508 & & & & $\sigma_{\mathrm{s}(0.2 \%)}[\mathrm{MPa}]$ \\
\hline A1 & 765 & 770 & 770 & & & & $\sigma_{\mathrm{m}}[\mathrm{MPa}]$ \\
\hline & 49 & 27 & 25 & & & & A $[\%]$ \\
\hline & 1045 & 970 & 900 & 850 & 1100 & 1050 & $\sigma_{\mathrm{s}(0.2 \%)}[\mathrm{MPa}]$ \\
\hline A1L & 1110 & 1060 & 1110 & & & & $\sigma_{\mathrm{m}}[\mathrm{MPa}]$ \\
\hline & 19 & 16 & 14 & & & & A $[\%]$ \\
\hline & 340 & 310 & 335 & & & & $\sigma_{\mathrm{s}(0.2 \%)}[\mathrm{MPa}]$ \\
\hline 5 & 684 & 670 & 695 & & & & $\sigma_{\mathrm{m}}[\mathrm{MPa}]$ \\
\hline & 59 & 36 & 34 & & & & $\mathrm{~A}[\%]$ \\
\hline & 850 & 830 & 750 & 720 & 930 & 860 & $\sigma_{\mathrm{s}(0.2 \%)}[\mathrm{MPa}]$ \\
\hline $4 \mathrm{~L}$ & 928 & 915 & 920 & & & & $\sigma_{\mathrm{m}}[\mathrm{MPa}]$ \\
\hline & 20 & 16 & 16 & & & & A $[\%]$ \\
\hline
\end{tabular}

Table 6: Tests results.

\section{RESULTS ANALYSIS} $\mathrm{n}$ the basis of microstructure analysis and of mechanical tests, the following remarks could be summarized:

- In the longitudinal section of material 5 (see Fig. 4a, typical rolling texture is shown; it implies that the steel annealing was not complete. As a consequence, a slight difference between the results of specimens "5BL" and "5BT" (Tab. 4) can be noticed; anyway, differences are not so evident to affect test results.

- Considering both the sampling direction and the specimen geometry, tensile resistance of the heat-treated steels is therefore practically identical as regards. As a consequence, it is possible to suppose that such behaviour is also valid for the radial direction.

The only difference is noticed in the measure of elongation between specimens "S" and "B" Tab. Q $)$. This difference, which is about $100 \%$, comes from the fact that the gage length of the two specimens is really different, hence the data cannot be compared. This measure is anyway appropriate between specimens with "B" geometry.

- The results of the tensile tests carried out on the cold worked materials indicate an increase by about $100 \%$ in the yield strength lengthwise and about $80 \%$ crosswise as regards the duplex stainless steel, as well as $150 \%$ lengthwise and $130 \%$ crosswise as regards the Super-austenitic steel. On the contrary, the ultimate tensile strength values increase of about $40 \%$ and $35 \%$, respectively. Elongation values decrease of about 60 and $66 \%$ respectively, considering measurements performed with specimens "S" as a reference.

- Compression tests results are characterized by a similar increase.

- The properties obtained from the specimens sampled in the radial direction are almost equal to the mean value, whilst the values obtained from the specimens sampled lengthwise and crosswise are divergent. Such a difference, already detected in the tensile tests, is however marked by the fact that, in this case, the specimens sampled crosswise result in higher values.

This fact can be explained by analyzing the cold worked steels microstructures (Figs. 3 and 5). Rolling produces a stressed stretching of grains and makes the structure similar to that of a plastic material reinforced by oriented fibres which have a resistance higher than that of the base material. These fibres reinforce the material in the direction they are arranged, if the material is subject to traction, whilst they have no influence if the material is subject to compression. The behaviour of the material, stressed radially, according to these considerations, should be similar, as it is, to the behaviour of the material stressed crosswise.

- Tab. 7 contains the percentage changes of the yield strength of the cold-rolled steels, referred to the reference steels. It can be noticed that investigated steels show a non-homogeneity indicated by the different behaviour under tensile and 
compression or by specimens coming from the same sampling direction, beyond an anisotropy indicated by the difference between the values obtained from the longitudinal and transversal specimens.

\begin{tabular}{cccccc}
\hline \multirow{2}{*}{ Material } & \multicolumn{2}{c}{ Tensile $[\Delta \%]$} & \multicolumn{3}{c}{ Compression $[\Delta \%]$} \\
A1L & $\mathrm{L}$ & $\mathrm{T}$ & $\mathrm{L}$ & $\mathrm{T}$ & $\mathrm{R}$ \\
4L & 100 & 80 & 75 & 125 & 115 \\
\hline
\end{tabular}

Table 7: Investigated steels yield strength vs specimen orientation and loading direction (deviation from annealed steels)

\section{CONCLUSIONS}

onsidering the experimental results and the microstructure analysis, the following conclusions could be summarized:

- Cold rolling process implies an increase in the yield strength and ultimate tensile strength values, higher for the yield strength, over $150 \%$ on the super-austenitic stainless steel, on the materials under test, whilst elongation values decrease significantly, over the $60 \%$,

- The anisotropy caused on the materials by the rolling process, as seen on the microstructures, is such as to determine differences by about $20 \%$ on the increase of the tensile yield strength, higher in the rolling direction. On the contrary this change cannot be detected either on the ultimate strength or on the elongation.

- The test procedure set up enabled the determination of the tensile transverse strength by the short specimen " $\mathrm{B}$ " and to compare the yield strength in all three directions by the compression specimen " $\mathrm{C}$ ",

- The compression tests in the three directions, pointed out a considerable non-homogeneity of the cold-rolled materials, since the values of the yield strength, measured under tensile and compression stresses, in the two directions were found not symmetrical.

\section{REFERENCES}

[1] Standard methods of tension testing of metallic materials ASTM E 8.

[2] Standard methods of compression testing of metallic materials at room temperature ASTM E 9. 